\title{
The Sensitivity and Specificity of Subjective Memory Complaints and the Subjective Memory Rating Scale, Deterioration Cognitive Observee, Mini-Mental State Examination, Six-Item Screener and Clock Drawing Test in Dementia Screening
}

\author{
S. Ramlalla J. Chipps ${ }^{b} \quad$ A.I. Bhigjee ${ }^{c} \quad$ B.J. Pillay ${ }^{d}$ \\ ${ }^{a}$ Department of Psychiatry, ${ }^{b}$ School of Nursing and Public Health, ${ }^{c}$ Department of \\ Neurology, and d Department of Behavioural Medicine, College of Health Sciences, \\ University of KwaZulu-Natal, Durban, South Africa
}

\section{Key Words}

Screening · Mini-Mental State Examination - Subjective memory complaints · Sensitivity ·

Specificity

\begin{abstract}
Background: The effectiveness of dementia screening depends on the availability of suitable screening tools with good sensitivity and specificity to confidently distinguish normal agerelated cognitive decline from dementia. The aim of this study was to evaluate the discriminant validity of 7 screening measures for dementia. Methods: A sample of 140 participants aged $\geq 60$ years living in a residential facility for the aged were assessed clinically and assigned caseness for dementia using the Diagnostic and Statistical Manual of Mental Disorders, 4th edition, text revised diagnostic criteria. Sensitivity and specificity of a selection of the following screening measures were tested using receiver operating characteristic (ROC) analysis for individual and combined tests: the Mini-Mental State Examination (MMSE), Six-Item Screener (SIS), Subjective Memory Complaint, Subjective Memory Complaint Clinical (SMCC), Subjective Memory Rating Scale (SMRS), Deterioration Cognitive Observee (DECO) and the Clock Drawing Test (CDT). Results: Using ROC analyses, the SMCC, MMSE and CDT were found to be 'moderately accurate' in screening for dementia with an area under the curve (AUC) $>0.70$. The AUCs for the SIS (0.526), SMRS (0.661) and DECO (0.687) classified these measures as being 'less accurate'. At recommended cutoff scores, the SMCC had a sensitivity of $90.9 \%$ and specificity of $45.7 \%$; the MMSE had a sensitivity of $63.6 \%$ and a specificity of $76.0 \%$, and the CDT had a sensitivity of $44.4 \%$ and a specificity of $88.9 \%$. Combining the SMCC and MMSE did
\end{abstract}


Ramlall et al.: The Sensitivity and Specificity of Subjective Memory Complaints and the SMRS, DECO, MMSE, SIS and CDT in Dementia Screening

not improve their predictive power except for a modest increase when using the sequential rule. Conclusion: The SMCC is composed of valid screening questions that have high sensitivity, are simple to administer and ideal for administration at the community or primary health care level as a first level of 'rule-out' screening. The MMSE can be included at a second stage of screening at the general hospital level and the CDT in specialist clinical settings. Sequential use of the SMCC and MMSE will improve the specificity of the former and the sensitivity of the latter.

Copyright (C) 2013 S. Karger AG, Basel

\section{Introduction}

Almost $60 \%$ of the world's dementia population resides in lower- and middle-income countries, with this figure predicted to increase to over $70 \%$ by 2050 [1]. Mild cognitive impairment (MCI) is an intermediate stage between the cognitive changes associated with normal aging and early dementia [2], and its prevalence ranges from 3 to 45\% [3], with an annual conversion rate from MCI to dementia ranging from 6 to $25 \%$ [2].

The challenges associated with identifying people with dementia are a significant barrier to its optimum management [4], and may contribute to treatment gaps as high as $90 \%$ [5]. In addition, despite limitations in currently available treatment, early detection of dementia through screening is beneficial for risk assessment and management [6], and is associated with high cost savings [7].

Screening refers to the use of measures to identify individuals at sufficient risk of a specific disorder to warrant further investigation or direct preventive action [8]. The ability of a measure to 'rule out' or 'rule in' the likely presence of a condition with minimal false positives and minimal false negatives is captured by quantification of its sensitivity, specificity and positive or negative predictive values $[9,10]$. In view of the considerable burden posed by dementia [11] and MCI [12], and the absence of pathognomonic biological markers for dementia [13], there is a need to identify suitable, effective screening measures that have been validated locally. The challenges associated with cross-cultural cognitive assessments are well documented [13-15]. Effective screening requires measures that are widely accessible, simple to administer, inexpensive, culturally appropriate, valid and reliable, that cause minimum discomfort and are sensitive to preclinical detection of disease states [9]. This is particularly important in low-income countries, where the language and culture may be very different from those where the measures have been developed. In addition, measures only suitable for applying in a research context must be distinguished from those that have practical utility in daily clinical settings in low-resource countries. Given the severe shortage of mental health professionals in low-income countries, including South Africa, measures need to be suitable for administration by lay or nonspecialist health care workers at busy primary care clinics, with minimum cost implications [16].

Cognitive decline in the elderly is believed to exist on a continuum ranging from normal age-related changes, to subjective impairment, MCI and dementia [17-19] with accompanying biomarker models being proposed [18]. Subjective ratings of health have been shown to be associated with impairment in functional and cognitive status [20] and brief self-reports, which can be easily obtained, have shown potential for predicting cognitive decline [21]. While the literature has traditionally focused on measures of objective cognitive impairment, there is increasing focus on the significance and measurement of subjective cognitive impairment, especially subjective memory impairment or subjective memory complaints.

The reported prevalence of subjective memory complaints varies widely from 26 [22] to $57 \%$ [23] depending on whether they are spontaneously reported or solicited, the types of 
Ramlall et al.: The Sensitivity and Specificity of Subjective Memory Complaints and the SMRS, DECO, MMSE, SIS and CDT in Dementia Screening

questions used to establish their presence, the nature of the sample (community vs. clinical) and age [24]. Objective cognitive impairment may be present in almost $50 \%$ of individuals with subjective memory complaints $[25,26]$, warranting clinicians to further investigate selfreports. Identifying valid measures of subjective cognitive impairment may therefore prove useful and have the potential to overcome some of the limitations related to the cross-cultural validity of objective cognitive assessment tools [27-29].

Subjective memory complaints have been associated with the presence of depression in the elderly [30] as well as increased risk for dementia [31]. Longitudinal studies confirm the association between subjective memory complaints and subsequent cognitive decline [17, $19,32,33$. The validity of subjective impairment as a correlate of organic pathology is supported by its association with neuroradiological changes in the absence of objective impairment [34, 35]. There is also a significant association between subjective memory complaints and cerebral white matter lesions which is independent of cognition and depression [36]. While the presence of subjective memory complaints correlates with a 20 - to 30 -percent likelihood of a diagnosis of dementia or MCI, their absence may be a 'reasonable' method of ruling out these conditions [24].

The aim of this study was therefore to evaluate the discriminant validity of 7 screening measures [Subjective Memory Complaint (SMC), Subjective Memory Rating Scale (SMRS), Deterioration Cognitive Observee (DECO), Mini-Mental State Examination (MMSE), Six-Item Screener (SIS) and Clock Drawing Test (CDT)] individually and in combination, the intention being to recommend a set of screening measures which could be applied in the multiracial, multilinguistic South African population in the primary health care context.

\section{Methods}

This study was a component of a study on dementia conducted in a group of homes for the elderly in Durban, KwaZulu-Natal, South Africa, which housed a total of 1,371 residents at the time of the study in 2010-2011. The homes are administered by a nongovernmental organization and cater for those needing frail care, and assisted and independent living for people aged 60 years and older. Inclusion criteria for the entire study were: residents who were 60 years and older, had a minimum of 8 years of formal schooling, were able to speak, read and write in English and give written, informed consent. Exclusion criteria were: residents with severe physical, mental or sensory handicaps that precluded their engagement in the assessment procedures.

The methodology and choice of instruments were designed to simulate local clinical practice at different levels of care. The 3 stages consisted of: (1) administration of dementia screening measures to a sample of the residents; (2) clinical diagnostic evaluation for dementia in a subsample of those screened, and (3) administration of neuropsychological measures to those assessed clinically.

Stage 1 consisted of 302 participants who were conveniently sampled to be screened for the presence of cognitive impairment. All 302 were administered the SMC and the MMSE [37]. For those participants who reported the presence of a subjective memory complaint, the SMRS [38] was also administered. If an informant was available, the informant DECO scale [39] was also administered $(n=76)$, with the results of this stage being reported separately elsewhere [40].

For stage 2, $140(46.4 \%)$ of the 302 screened participants (38 screen positives and 102 randomly selected screen negatives on the MMSE) had a clinical diagnostic evaluation conducted in English by psychiatrists [41]. The psychiatrists were blinded to the results of the screening in stage 1 and used a standardized clinical diagnostic assessment tool developed for this stage of the study. While several formal and wellresearched tools exist for dementia diagnosis [42-44], many are applicable only in research contexts, this having implications for cost and skills in administration, while others require the presence of an informant [45-48], which is not always possible. The structured questionnaire used in our study consisted of two components and was designed to simulate naturalistic clinical practice in respect of cognitive assessment of the elderly. Firstly, it contained items for the evaluation of clinical and historical risk factors for dementia and included a subjective cognitive impairment measure [Subjective Memory Complaint Clinical (SMCC)]. 
Ramlall et al.: The Sensitivity and Specificity of Subjective Memory Complaints and the SMRS, DECO, MMSE, SIS and CDT in Dementia Screening

Secondly, it included the mental state examination (comprising bedside cognitive assessments of memory, language, praxis and executive functioning), self-reported assessments of functional abilities (basic and instrumental activities of daily living) and a physical examination. Following the clinical diagnostic assessments, a consensus panel consisting of 3 specialists (neurologist, clinical psychologist and psychiatrist) assigned diagnoses of dementia, current major depression and delirium according to the Diagnostic and Statistical Manual of Mental Disorders, 4th edition, text revised (DSM-IV-TR) criteria [49] and MCI [50] to all 140 participants. The panel was blinded to the participants' performance scores on the various screening measures. In the third stage, 117 participants completed a battery of neuropsychological measures which included the CDT [51]. The overall study received ethical approval from the Biomedical Research Ethics Committee of the University of KwaZulu Natal and the elderly gave written, informed consent to participate.

\section{Clinical Classification ('Gold Standard')}

For the purposes of this study, the following applies: dementia was diagnosed using the DSM-IV-TR. Criteria A and B for Alzheimer's and vascular dementia were applied to assign a general diagnosis of dementia without reference to etiology. A clinical diagnosis was used as the 'gold standard' for dementia [52, 53].

MCI was diagnosed using the criteria contained in the report of the International Working Group on Mild Cognitive Impairment. These were: the presence of subjective cognitive impairment (self- or informantreported), objective evidence of cognitive impairment in the presence of high scores for activities of daily living and normal or minimally impaired instrumental activities of daily living functions [50]. Subjective memory impairment was assessed through solicited self-report and objective evidence of cognitive impairment was based on the performance of participants in the various cognitive domains assessed in the clinical evaluation (stage 2).

Nondementia controls were those participants who did not meet the criteria for dementia. The controls were those participants who did not meet the criteria for MCI or for dementia.

\section{Screening Measures}

Although there are almost 150 cognitive screening measures cited in the literature [54], there is no consensus on what domains should be measured [13].

Seven screening measures were chosen with regard to relevance and utility in low-resourced contexts and with the view to developing an assessment algorithm for widespread local implementation. Apart from the neuropsychological battery of tests, all the measures used in this study were deemed to be suitable for use by nonspecialist clinical personnel and, except for the DECO, were not dependent on the availability of an informant.

One of the challenges associated with interpreting the significance of subjective memory complaints has been identified as the inconsistency in its definition across studies [55]. By utilizing 3 different assessment measures for subjective memory complaint (1-3 below), we hoped to identify one that would be most sensitive and useful for screening.

(1) Subjective Memory Complaint. The SMC is a single-domain screening measure assessing memory through a 'yes/no' response to the question: 'Are you experiencing any difficulty with your memory?'

(2) Subjective Memory Complaint Clinical. The SMCC is a single-domain screening measure assessing memory through affirmative responses to 7 questions on memory recall problems experienced at least once a week over the last year. The participant is confronted with 7 commonly occurring situations requiring memory recall, 6 short-term and 1 long-term items (table 3). The evaluation of the SMCC is distinguished from the SMC by the specification of duration, frequency and nature of the memory complaint. As memory behaviors occur in specific behavioral contexts and most memory questionnaires focus on context-free memory domains, we decided to evaluate specific memory behaviors. This is based on the behavioral specificity hypothesis that 'individuals are capable of accurately reporting memory-related problems in everyday life, provided that questions are specific to the behaviours in question' [56]. The descriptive subjective memory items used in our study were based on commonly encountered clinical experiences of patients in a psychiatric hospital setting which were further specified for duration and frequency. Their face validity was confirmed by 2 psychologists and 3 psychiatrists. The SMCC was coded as positive if the participant reported difficulties with at least 1 of the 7 situations presented. A positive association has been shown between the type and number of subjective memory complaints and objective cognitive performance, with 'finding one's way around familiar streets' identified as being one type of memory complaint that was more likely than others to be associated with cognitive impairment [57]. 
(3) Subjective Memory Rating Scale. This is a 5-item single-domain scale that assesses subjective deterioration of memory over a 10- to 20-year period in 5 situations [38]. Each item is scored on a 5-point Likert scale. The maximum score that may be obtained on this scale is 25 and a score of $\geq 20$ suggests memory impairment. While there is no information on the sensitivity and specificity of the SMRS, subjective memory questionnaires have a pooled sensitivity and specificity of 43 and $85.8 \%$, respectively [24]. There are at least 15 variations of the use of a single question, and at least 10 sets of questions in the literature [55] to assess subjective memory impairment. The SMRS used in this study has not been as extensively researched as the CAMDEX [58] subset of items $[59,60]$ and the MAC-Q [61-64]. The MAC-Q has recently been found to be greatly affected by affect and was not recommended for cognitive screening [65]. The Memory Complaint Scale has only recently been proposed for further research [66]. The SMRS was chosen for its brevity, simplicity and scoring method - characteristics that could lend it to easy administration by nonprofessionals, translation into local languages and utility for elderly with low literacy, should it prove to have validity for dementia screening.

(4) Deterioration Cognitive Observee. This is a multidomain 19-item screening test which is considered not to be affected by the participant's education as it relies on an informant to complete the questionnaire [39]. At a cutoff score of $\leq 24$, the DECO has a sensitivity of $79 \%$ and specificity of $90 \%$ in detecting dementia [39]. The DECO has discriminability for mild, moderate and severe dementia [13] and has been found to be useful in predicting mild and moderate dementia in South Africa [67]. The DECO was therefore chosen above the more widely researched IQCODE [68].

(5) Mini-Mental State Examination. It is a multidomain clinician-administered tool that yields a maximum score of 30 . The most widely used cutoff score for cognitive impairment is $\leq 23$. In community settings, the MMSE has a pooled sensitivity and specificity of 85.1 and $85.5 \%$, respectively [69]; its sensitivity and specificity in the South African population have not been determined. The MMSE was selected as it is the most widely used screening instrument in clinical and research settings $[69,70]$, despite the emergence of many new tools over the last 10 years [71]. To our knowledge, its validity in the local setting has not been determined, yet this is necessary in order to be able to reference other screening tools against it in future. Its recently introduced copyright restrictions and related costs may prevent its widespread use in low-resource settings in the future.

(6) Six-Item Screener. The SIS [72] is a brief multidomain tool comprising 3 temporal orientation items and the 3 recall items of the MMSE, resulting in a maximum total score of 6 . It has been found to be reliable and has the full psychometric properties of the full MMSE. Using a cutoff score of $\leq 3$, the SIS has a sensitivity and specificity of 88.7 and $88 \%$, respectively, for the diagnosis of dementia [72].

(7) Clock Drawing Test. This is a screening test for dementia [73] that assesses visuospatial, constructional and executive functions and is classified as a single-domain test [74]. In this study, the free-drawing version with the ' 10 past 11' time setting instruction was used. The 10-point scoring method of Rouleau et al. $[75,76]$ was used and a cutoff of $\leq 6$ was applied. The CDT has been shown to have good correlation with the MMSE. It is nonthreatening to patients and has been identified as a good screening test for moderate and severe, but not mild, dementia. Lower scores are obtained with increasing age, low education and depression. It has the advantage over other screening tests in that the clock drawings can serve as a visual record of the cognitive status of an individual which can be compared over time [77].

The quoted sensitivities and specificities of the above measures emanate from studies conducted in countries other than South Africa and are in reference to a diagnosis of dementia only.

Measures of Predictive Validity for Dementia versus Nondementia

Though community settings may require screening measures with a lower sensitivity compared to clinical settings [10], sensitivity and specificity of $>80 \%$ were set as acceptable levels for the measures [78]. The ability of a measure to case-find or 'rule in' dementia with minimal false negatives is its positive predictive value (PPV), and the ability of a measure to screen or 'rule out' a diagnosis with minimal false positives is its negative predictive value (NPV) $[9,79]$. The PPV and NPV are considered most relevant for clinicians [80]. More often receiver operating characteristic (ROC) curves are used where the area under the ROC curve (AUC) summarizes the diagnostic accuracy of a tool on all possible cutoff scores, giving equal weighting to sensitivity and specificity and allowing for the comparison of the discriminatory validity of different cognitive tests $[13,81]$. Though AUC values of $<0.8$ are considered of 'questionable utility' [10], in this study, AUC values of 0.5 were classified as noninformative; $0.5<$ AUC $\leq 0.7$ less accurate; $0.7<$ AUC $\leq 0.9$ moderately accurate; $0.9<\mathrm{AUC}<1$ highly accurate with the perfect test having an AUC $=1$ [82]. In this study, the Youden index (J) was used as a specific metric measurement of overall diagnostic effectiveness as a function of optimal sensitivity and specificity [83]. 
Ramlall et al.: The Sensitivity and Specificity of Subjective Memory Complaints and the SMRS, DECO, MMSE, SIS and CDT in Dementia Screening

\section{Statistical Analysis}

The data were analyzed in 3 components: demographic details, performance of the 7 measures, and performance of the combined screening measures. Data were analyzed using IBM SPSS19 and ROC curves were calculated using MedCalc software. The demographic variables included age, gender, race and education level; average test scores and the proportion of participants with cognitive impairment were calculated for each of the classification categories and compared using $\chi^{2}$ tests. The clinically assigned diagnoses (dementia and MCI) were used as the gold standard to calculate the sensitivity, specificity, PPV and NPV for the subjective and objective screening tools using their standard cutoff values. In addition, for each tool, the AUC with 95\% confidence intervals (CIs), optimal cutoff scores (Youden index), and cutoff values for set sensitivities and specificities of $80 \%$ were calculated using ROC analysis.

The single-domain (SMCC) and multidomain (MMSE) screening measures that each displayed the best accuracy for screening (AUC $>0.70$ ) were then combined to determine whether the 2 tests together provided any additional information for dementia prediction over that given by either test alone. Three different methods were used: logistic regression, the compensatory ('or') rule and the conjunctive ('and') rule [84]. Differences in the sensitivity and specificity of individual and combinations of tests were evaluated using 95\% CIs.

The SMCC and MMSE were entered simultaneously to determine which variables independently predicted dementia when adjusting for scores on the remaining tests. Two stepwise approaches were used (forward and backward) with the SMCC forced into the model and the MMSE as candidate for stepwise entry. The probability was 0.05 for stepwise entry and 0.10 for removal, and because similar models were elicited using forward and backward stepwise methods, only results from the forward stepwise regressions are reported. The odds ratios and CIs were reported for each measure, and the percentage of those correctly classified as demented is reported. ROC curves and the AUC were generated to graphically and quantitatively reflect the ability of the combined models derived from logistic regression to discriminate between dementia and nondementia controls.

\section{Results}

The demographic results will be followed by a review of the performance of the 7 measures and the results of the analysis of the combination of the tests that performed the best.

The 140 participants comprised $97(69.3 \%)$ females and $43(30.7 \%)$ males with an average age of $75.2 \pm 8.9$ years. There was a significant association between increasing age and increasing cognitive impairment $(F=5.0, p=0.008$; table 1$)$. There were $65(46.4 \%)$ white, $41(29.3 \%)$ colored, $28(20 \%)$ Asian and 6 (4.3\%) black participants. One hundred and six participants $(75.7 \%)$ had less than 12 years of education and $11(7.9 \%)$ participants had more than 12 years of education; significant differences were found in education levels between controls and MCI participants ( $\mathrm{p}=0.041$ ) (table 1).

While all 140 of the sample had MMSE, SIS and SMCC scores, SMRS scores were only available for those who reported the presence of subjective impairment $(n=69)$, and DECO scores were only available for those participants who had contactable informants $(n=34)$ [40]. The prevalence data for dementia and MCI are reported fully in a separate paper [41].

Table 1 also reports on the performance of the various assessment measures. The prevalence of screen positives on the various measures was compared across the three classification groups (dementia, MCI, controls) using standard cutoff scores. All the measures, except for the SIS and DECO, were significantly different between the classification groups. The MMSE, SMCC, SMRS and CDT were able to significantly discriminate between controls and those with MCI and dementia (table 1). 
Table 1. Demographic and psychometric data according to diagnostic categories

\begin{tabular}{|c|c|c|c|c|c|}
\hline & $\begin{array}{l}\text { Dementia } \\
(\mathrm{n}=11 ; 7.9 \%)\end{array}$ & $\begin{array}{l}\text { MCI } \\
(n=38 ; 27.1 \%)\end{array}$ & $\begin{array}{l}\text { Controls } \\
(n=91 ; 65 \%)\end{array}$ & Statistic & $\mathrm{p}$ \\
\hline Age & $77.2 \pm 7.9$ & $75.8 \pm 8.1$ & $72.1 \pm 6.8$ & $\mathrm{~F}=5.0$ & $0.008^{*}$ \\
\hline Race & & & & $\chi^{2}=15.0$ & 0.078 \\
\hline Asian & 0 & $6(15.8)$ & $22(24.2)$ & & \\
\hline Black & $1(9.1)$ & $2(5.3)$ & $3(3.3)$ & & \\
\hline Colored & $1(9.1)$ & $15(39.5)$ & $25(27.5)$ & & \\
\hline White & $9(81.8)$ & $15(39.5)$ & $41(45.1)$ & & \\
\hline Gender & & & & $\chi^{2}=3.7$ & 0.165 \\
\hline Female & 9 (81.8) & $30(78.9)$ & $58(63.7)$ & & \\
\hline Male & $2(18.2)$ & 8 (21.1) & $33(36.3)$ & & \\
\hline Years of education & $10.3 \pm 2.6$ & $9.3 \pm 1.6$ & $10.3 \pm 2.1$ & $F=3.3$ & $0.041^{*}$ \\
\hline \multicolumn{6}{|c|}{ Performance of assessment measures } \\
\hline SMC present & $7(63.6)$ & $26(68.4)$ & $33(36.3)$ & $\chi^{2}=12.5$ & $0.002^{*}$ \\
\hline $\operatorname{SMCC} \geq 1$ & $10(90.9)$ & $38(100)^{a}$ & $32(35.2)$ & $\chi^{2}=61.4$ & $<0.001^{*}$ \\
\hline SMRS $\geq 20$ & 1 (14.3) & $8(30.8)$ & $3(9.1)$ & $\chi^{2}=4.5$ & 0.080 \\
\hline DECO $\leq 24$ & $1(50)$ & $1(16.7)$ & 3 (11.5) & $\chi^{2}=2.6$ & 0.301 \\
\hline MMSE $\leq 23$ & $7(63.6)$ & $12(31.6)$ & $19(20.9)$ & $\chi^{2}=8.5$ & $0.010 *$ \\
\hline SIS $\leq 4$ & $5(45.5)$ & 22 (57.9) & $46(50.5)$ & $\chi^{2}=0.8$ & 0.712 \\
\hline $\mathrm{CDT} \leq 6$ & $4(44.4)$ & 5 (16.7) & $7(9)$ & $\chi^{2}=7.5$ & $0.009 *$ \\
\hline
\end{tabular}

Figures in parentheses are percentages. Spearman's $\chi^{2}$ test and Fisher's exact test were used. Significance set at $95 \%, * \mathrm{p}<0.05$.

a The presence of at least 1 SMCC was a diagnostic requirement for MCI.

\section{Performance of the Seven Measures}

Table 2 summarizes the ROC analysis data for each of the measures (excluding SMC ${ }^{1}$ ) with sensitivity, specificity, PPV, NPV and AUC values for detecting dementia based on their recommended cutoff scores. In addition, the optimum cutoff scores that should be applied to optimize the trade-off between sensitivity and specificity are reported, together with the recommended cutoff scores if a fixed sensitivity or specificity of $80 \%$, respectively, was required.

Using the acceptable level of $80 \%$ for sensitivity, only the SMCC had a sensitivity $>80 \%$ (90.9\%), followed by the MMSE with a sensitivity of $63.6 \%$. In terms of specificity, the SMRS (81.4\%), DECO (87.5\%) and CDT (88.9\%) achieved a specificity $>80 \%$; however, the MMSE had a specificity of 76\% (table 3). With the exception of the SMCC and SIS, adjusting the cutoff scores in order to optimize the balance between sensitivity and specificity values resulted in increasing one at the expense of the other being lowered. Increasing the cutoff score of the MMSE from $\leq 23$ to $\leq 24$ increased its sensitivity from 63.6 to $81.8 \%$ (table 2). The SIS, comprising a subset of MMSE items, was evaluated for its potential to replace the MMSE, which is considered by some to be too lengthy for administration. However, in this study, the SIS displayed sensitivity and specificity values $<50 \%$, with an AUC of 0.526 ( $p=0.777$ ).

The NPVs ranged from $88.9 \%$ for the SMRS to $98.3 \%$ for the SMCC identifying the measures as having a good 'rule-out' value (not dementia cases), thus good for screening. All the measures recorded very low PPVs ranging from $6.8 \%$ for the SIS to $25.0 \%$ for the CDT, suggesting a poor 'rule-in' value (finding possible dementia cases).

${ }^{1}$ This categorical measure was not suitable for ROC analysis. 
Table 2. Predictive validity of screening measures for dementia

\begin{tabular}{|c|c|c|c|c|c|c|c|c|}
\hline & $\begin{array}{l}\text { Sensitivity } \\
\% \\
(95 \% \mathrm{CI})\end{array}$ & $\begin{array}{l}\text { Specificity } \\
\% \\
(95 \% \mathrm{CI})\end{array}$ & $\begin{array}{l}\text { PPV, \% } \\
(95 \% \mathrm{CI})\end{array}$ & $\begin{array}{l}\text { NPV, } \% \\
(95 \% \mathrm{CI})\end{array}$ & $\begin{array}{l}\text { AUC } \\
(95 \% \mathrm{CI}) \\
\text { p value }\end{array}$ & $\begin{array}{l}\text { Optimum cutoff } \\
\text { caseness } \\
\text { (sensitivity, } \\
\text { specificity in \%) } \\
\text { Youden index }\end{array}$ & $\begin{array}{l}\text { Cutoff score, } \\
\text { sensitivity } 80 \% \text {, } \\
\text { specificity in \%a }\end{array}$ & $\begin{array}{l}\text { Cutoff score, } \\
\text { sensitivity in } \\
\%, \text { specificity } \\
80 \%^{\mathrm{b}}\end{array}$ \\
\hline SMCC & $\begin{array}{l}90.9 \\
(57.1-99.5)\end{array}$ & $\begin{array}{l}45.7 \\
(37.0-54.7)\end{array}$ & $\begin{array}{l}12.5 \\
(6.5-22.2)\end{array}$ & $\begin{array}{l}98.3 \\
(89.9-99.9)\end{array}$ & $\begin{array}{l}0.717 \\
(0.635-0.790) \\
p=0.004^{*}\end{array}$ & $\begin{array}{l}>0 \\
(90.9,45.7) \\
J=0.37\end{array}$ & $>0.4,80,51.0$ & $>2.1,52.1,80$ \\
\hline SMRS & $\begin{array}{l}14.3 \\
(0.8-58.0)\end{array}$ & $\begin{array}{l}81.4 \\
(68.7-89.9)\end{array}$ & $\begin{array}{l}8.3 \\
(0.4-40.2)\end{array}$ & $\begin{array}{l}88.9 \\
(76.7-95.4)\end{array}$ & $\begin{array}{l}0.661 \\
(0.537-0.771) \\
p=0.05\end{array}$ & $\begin{array}{l}>16 \\
(100,32.3) \\
J=0.32\end{array}$ & $>16,80,46.9$ & $>18,22.3,80$ \\
\hline DECO & $\begin{array}{l}50.0 \\
(2.7-97.3)\end{array}$ & $\begin{array}{l}87.5 \\
(70.1-96.0)\end{array}$ & $\begin{array}{l}20.0 \\
(1.0-70.1)\end{array}$ & $\begin{array}{l}96.6 \\
(80.4-99.8)\end{array}$ & $\begin{array}{l}0.687 \\
(0.506-0.835) \\
p=0.462\end{array}$ & $\begin{array}{l}\leq 17 \\
(50,93.8) \\
J=0.44\end{array}$ & $\leq 32,80,41.3$ & $\leq 27,50.0,80$ \\
\hline MMSE & $\begin{array}{l}63.6 \\
(31.6-87.6)\end{array}$ & $\begin{array}{l}76.0 \\
(67.5-82.9)\end{array}$ & $\begin{array}{l}18.4 \\
(8.3-34.9)\end{array}$ & $\begin{array}{l}96.1 \\
(89.7-98.7)\end{array}$ & $\begin{array}{l}0.770 \\
(0.691-0.838) \\
p<0.001^{*}\end{array}$ & $\begin{array}{l}\leq 24(81.8,66.7) \\
J=0.49\end{array}$ & $\leq 24,80,67.6$ & $\leq 23,63.6,80$ \\
\hline SIS & $\begin{array}{l}45.5 \\
(18.1-75.4)\end{array}$ & $\begin{array}{l}47.3 \\
(38.5-56.2)\end{array}$ & $\begin{array}{l}6.8 \\
(2.5-15.9)\end{array}$ & $\begin{array}{l}91.0 \\
(80.9-96.3)\end{array}$ & $\begin{array}{l}0.526 \\
(0.349-0.703) \\
p=0.777\end{array}$ & $\begin{array}{l}>4 \\
(54.6,52.7) \\
J=0.07\end{array}$ & $>3,80,23.8$ & $>5,19.9,80$ \\
\hline CDT & $\begin{array}{l}44.4 \\
(15.3-77.3)\end{array}$ & $\begin{array}{l}88.9 \\
(81.0-93.9)\end{array}$ & $\begin{array}{l}25.0 \\
(8.3-52.6)\end{array}$ & $\begin{array}{l}95.0 \\
(88.3-98.2)\end{array}$ & $\begin{array}{l}0.732 \\
(0.642-0.810) \\
p=0.012^{*}\end{array}$ & $\begin{array}{l}\leq 5 \\
(44.4,91.7) \\
J=0.36\end{array}$ & $\leq 9,80,50.5$ & $\leq 6.8,44.4,80$ \\
\hline
\end{tabular}

Using De Long et al. [85], binomial exact CI for AUC, and optimal Youden index (J = sensitivity and 1 - specificity) were calculated. Significance set as $\mathrm{p}<0.05$ (asterisk). ${ }^{a}$ Sensitivity set at $80 \%$. ${ }^{\mathrm{b}}$ Specificity set at $80 \%$.

However, only the SMCC (AUC $=0.717, \mathrm{p}=0.004)$, MMSE (AUC $=0.770, \mathrm{p}<0.001)$ and CDT (AUC $=0.732, p=0.012$ ) had AUC scores of $>0.70$, thereby meeting the criteria for 'moderate reliability' as screening tools and warranting further investigation [82].

The SMCC had moderate discriminatory power to correctly classify those with and without dementia (AUC $=0.717, \mathrm{p}=0.004$ ) and potential utility as a single-domain screening test. At the standard cutoff scores of $>1$, the SMCC had a sensitivity of $91 \%$ and a specificity of $46 \%$. This means that the presence of at least 1 subjective memory complaint correctly identified $91 \%$ of the 11 participants with dementia, but only correctly distinguished $46 \%$ of the 129 nondementia participants as such. In terms of whether the measure would predict the probability of having dementia, the proportion of people with a positive SMCC score who had dementia was low (PPV $=13 \%$ ), but the proportion of people with a negative SMCC score who did not have dementia was high (NPV $=98 \%)$, thus confirming that the SMCC would be useful for 'ruling out' dementia.

With these findings, it appeared that the SMCC could be used as an appropriate first-step screening measure where false positives would be included for further screening. The SMCC measure had a high reliability (internal consistency) with a Cronbach's alpha of 0.745 , with 2 of the 7 individual items significantly associated with dementia. These were: 'difficulty remembering what happened in the last few days' $\left(\chi^{2}=8.5, p=0.008\right)$ and 'difficulty remembering the names of people you have known a long time' $\left(\chi^{2}=5.6, p=0.025\right)$ (table 3). 
Table 3. Performance of SMCC items

\begin{tabular}{|c|c|c|c|c|}
\hline \multicolumn{2}{|c|}{ Item } & \multirow{2}{*}{$\begin{array}{l}\begin{array}{l}\text { Dementia } \\
(\mathrm{n}=11)\end{array} \\
7(63.6 \%)\end{array}$} & \multirow{2}{*}{$\begin{array}{l}\begin{array}{l}\text { Nondementia } \\
(\mathrm{n}=129)\end{array} \\
30(23.3 \%)\end{array}$} & \multirow{2}{*}{$\begin{array}{l}\text { Test } \\
\chi^{2}=8.5, p=0.008^{*}\end{array}$} \\
\hline 1 & $\begin{array}{l}\text { Difficulty remembering things that had happened } \\
\text { in the last few days? }\end{array}$ & & & \\
\hline 2 & $\begin{array}{l}\text { Difficulty remembering the names of common } \\
\text { objects? }\end{array}$ & $2(18.2 \%)$ & $12(9.3 \%)$ & $\chi^{2}=0.9, p=0.302$ \\
\hline 3 & $\begin{array}{l}\text { Difficulty remembering where you left your } \\
\text { belongings? }\end{array}$ & $5(45.5 \%)$ & $35(27.1 \%)$ & $\chi^{2}=1.7, p=0.294$ \\
\hline 4 & $\begin{array}{l}\text { Difficulty remembering the names of people you } \\
\text { have known for a long time? }\end{array}$ & $8(72.7 \%)$ & $47(36.4 \%)$ & $\chi^{2}=5.6, p=0.025^{*}$ \\
\hline 5 & $\begin{array}{l}\text { Difficulty remembering the names of people who } \\
\text { you had met within the last week? }\end{array}$ & $6(54.5 \%)$ & $44(34.1 \%)$ & $\chi^{2}=1.8, p=0.200$ \\
\hline 6 & Difficulty finding your way around your home? & $1(9.1 \%)$ & $4(3.1 \%)$ & $\chi^{2}=1.1, p=0.340$ \\
\hline 7 & $\begin{array}{l}\text { Difficulty finding your way around other places (e.g. } \\
\text { shopping center/home of a friend/relative/church)? }\end{array}$ & $1(9.1 \%)$ & $7(5.4 \%)$ & $\chi^{2}=0.3, p=0.489$ \\
\hline
\end{tabular}

Differences were tested using Fisher's exact test. Significance was set at 95\%, ${ }^{*} \mathrm{p}<0.05$.

The SMCC also displayed higher sensitivity ( 90.9 vs. $63.6 \%$ ), PPV (12.5 vs. $10.6 \%$ ) and NPV (98.3 vs. $94.6 \%$ ) than the SMC. The SMCC defines the duration, frequency and nature of the memory complaints as opposed to the SMC, which merely confirms the presence of any subjective memory complaint. These results suggest that defining subjective cognitive impairment with greater specificity may result in higher predictive validity.

The MMSE was also found to have moderate discriminative ability as a screening measure for dementia (AUC $=0.770, \mathrm{p}<0.001$ ), confirming its utility as a multidomain screening test. At the standard cutoff score of $\leq 23$, the MMSE had a sensitivity of $63.6 \%$ and a specificity of $76 \%$, meaning that the MMSE at that cutoff score correctly identified $63.6 \%$ of the 11 participants who had dementia, and misclassified $24 \%$ of the 129 participants without dementia as having dementia. Increasing the cutoff score to $\leq 24$ improved the sensitivity of the MMSE to $81.8 \%$ while reducing its specificity to $66.7 \%$.

The MMSE NPV was high with $96.1 \%$ of participants with a negative test not having dementia, but it had a low PPV with $18.4 \%$ of participants with a positive test actually having dementia.

The CDT also showed potential as a screening measure [86] and displayed a similar moderate discriminability to the MMSE in identifying participants with and without dementia (AUC $=0.731, p=0.012$ ). At standard cutoff scores of $\leq 6$, the CDT had a sensitivity of $44.4 \%$ and a specificity of $88.9 \%$. Reducing the cutoff score to $\leq 5$ did not improve the sensitivity but increased the specificity to $91.7 \%$.

The CDT NPV was also high with $95 \%$ of participants with a negative test not having dementia, but the CDT PPV was low with $25 \%$ of participants with a positive test actually having dementia. The findings from this study confirmed that the CDT would also be useful for screening and 'ruling out' dementia. 
Ramlall et al.: The Sensitivity and Specificity of Subjective Memory Complaints and the SMRS, DECO, MMSE, SIS and CDT in Dementia Screening

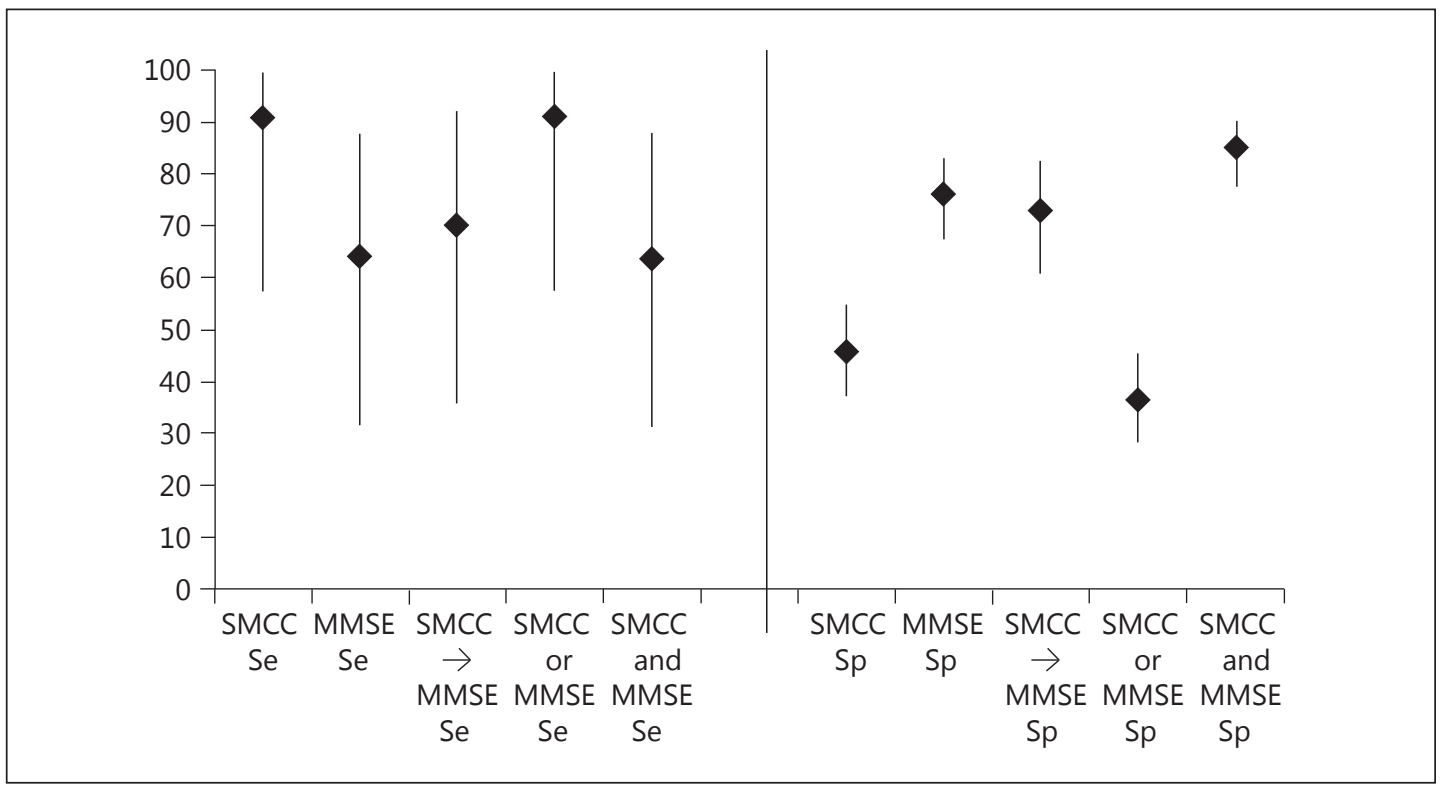

Fig. 1. Sensitivity and specificity of combination of measures (95\% CI). Se = Sensitivity; $\mathrm{Sp}=$ specificity.

\section{Combining Screening Measures}

Combining measures in parallel or sequentially can address the challenges of the 'tradeoff' between sensitivity and specificity [9, 80, 84]. The SMCC (a single-domain measure) and the MMSE (a multidomain measure) were combined in 4 different ways and tested for improvements in accuracy of screening for dementia compared to the use of the MMSE or SMCC alone (table 4).

Sequential Combination. Starting with the single-domain measure, followed by the multidomain measure, all participants who screened positive on the SMCC $(n=80)$ were selected for further screening. The MMSE results on the 80 participants identified 26 as scoring $\leq 23$. Sequentially combining the MMSE with SMCC increased the discriminatory power of the MMSE with the AUC increasing from $0.770(95 \%$ CI $0.62-0.919, \mathrm{p}=0.004)$ to $0.774(95 \% \mathrm{CI}$ $0.602-0.945, p=0.005$ ) (table 4 ), and resulted in an increased sensitivity of $70 \%$ (95\% CI $35.4-91.9$, n.s.) and a decreased specificity of $72.9 \%$ (95\% CI 60.7-82.5, n.s.) (fig. 1).

Compensatory Combination. Using the compensatory rule, the two measures were combined by classifying participants as screen positive if either measure had a positive result. Consistent with this interpretation, combining two tests in this manner should increase sensitivity above that of either test used alone. However, because only participants with negative results on both tests are classified as controls, the specificity of the combination cannot be greater than that of either test [84].

Combining the presence of a positive SMCC or a positive MMSE score resulted in 92 participants meeting caseness for dementia on either of these measures $(n=92)$, compared to 80 on the SMCC and 38 on the MMSE. Combining these tests reduced the discriminatory power of the measures (AUC $=0.637,95 \%$ CI 0.49-0.783, $\mathrm{p}=0.133$ ) (table 4 ) and resulted in a sensitivity of $90.9 \%$ (95\% CI 57.1-99.5), which was similar to the SMCC but higher than the MMSE (n.s.). The sensitivity for these 36.4\% (95\% CI 28.3-45.4) screen positives was lower than that in the SMCC (n.s.) and significantly lower than that in the MMSE individually (fig. 1).

Conjunctive Combination. Using the conjunctive rule, two tests are combined by classifying patients as having dementia if the patient scored positive on both tests. Such a combi- 


\section{Dementia}

Cognitive Disorders
Dement Geriatr Cogn Disord 2013;36:119-135

DOI: $10.1159 / 000350768$

Ramlall et al.: The Sensitivity and Specificity of Subjective Memory Complaints and the SMRS, DECO, MMSE, SIS and CDT in Dementia Screening

Table 4. Predictive validity measures of various combinations of SMCC and MMSE

\begin{tabular}{|c|c|c|c|c|c|c|}
\hline Cases & Sensitivity & NPV & Specificity & PPV & AUC & $\mathrm{p}$ \\
\hline $\begin{array}{l}\text { SMCC alone } \\
\qquad(\mathrm{n}=80,57.1 \%)\end{array}$ & $90.9(57.1-99.5)$ & 98.3 (89.9-99.9) & $45.7(37.0-54.7)$ & $12.5(6.5-22.2)$ & $0.717(0.635-0.790)$ & $0.004^{*}$ \\
\hline $\begin{array}{l}\text { MMSE alone } \\
\quad(\mathrm{n}=38,27.1 \%)\end{array}$ & $63.6(31.6-87.6)$ & 96.1 (89.7-98.7) & $76.0(67.5-82.9)$ & 18.4 (8.3-34.9). & $0.770(0.691-0.838)$ & $<0.001^{*}$ \\
\hline $\begin{array}{l}\text { Sequential rule } \\
\text { (SMCC } \rightarrow \text { MMSE) } \\
\quad(\mathrm{n}=80 \rightarrow 26,32.5 \%)\end{array}$ & $70(35.4-91.9)$ & $94.4(83.7-98.6)$ & $72.9(60.7-82.5)$ & $26.9(12.4-48.1)$ & $0.774(0.602-0.945)$ & $0.005^{*}$ \\
\hline $\begin{array}{l}\text { Compensatory rule } \\
\text { (either test is positive) } \\
(\mathrm{n}=92,65.7 \%) \\
\end{array}$ & $90.9(57.1-99.5)$ & $97.9(87.5-99.9)$ & $36.4(28.3-45.4)$ & $10.9(5.6-19.5)$ & $0.637(0.49-0.783)$ & 0.133 \\
\hline $\begin{array}{l}\text { Conjunctive rule } \\
\text { (positive on both tests) } \\
\quad(\mathrm{n}=26,18.6 \%)\end{array}$ & $63.6(31.6-87.6)$ & $96.5(90.7-98.9)$ & $85.3(77.7-90.6)$ & $26.9(12.4-48.1)$ & $0.745(0.572-0.917)$ & $0.007^{*}$ \\
\hline
\end{tabular}

nation of tests should improve specificity over that of either test used alone, but the sensitivity of the combination can be no higher than that of either test [84].

When the tests were used individually, 80 and 38 participants screened positive on the SMCC and MMSE, respectively. When a participant screened positive on both measures, only 26 participants met caseness for dementia. Screening positive on both measures resulted in a sensitivity of $63.6 \%$ (95\% CI 31.6-87.6), similar to that in the MMSE but lower than that in the SMCC (n.s.) (fig. 4). The specificity was $85.3 \%$ (95\% CI 77.7-90.6), which was significantly higher than that in the SMCC and MMSE (n.s.) on their own (fig. 1). This combination of measures resulted in moderate discriminatory power with an AUC of 0.745 (95\% CI 0.572 0.917, $\mathrm{p}=0.007$ ) (table 4).

Probability Combination. Logistic regression was used to combine the SMCC and MMSE scores using a mathematical calculation of probability to determine which combination of tests best discriminated individuals with dementia from those without dementia. The SMCC on its own was a significant predictor of group membership (step 1 ; Wald $\chi^{2}=5.6$, odds ratio $=1.5,95 \%$ CI 1.1-2.0, $\mathrm{p}=0.018$ ). With each 1-point increase in SMCC score, participants were 1.5 times more likely to be diagnosed with dementia and the measure correctly classified $92.1 \%$ of participants with dementia as having dementia. The addition of the MMSE (step 2; Wald $\chi^{2}=6.8, \mathrm{p}=0.009$ ) improved the identification of dementia and the discriminatory power of SMCC score and MMSE score combined increased AUC to 0.771 (95\% CI $0.610-0.933, p=0.003$ ). Using the SMCC as a categorical measure (cutoff score of $\geq 1$ SMCC) and combining the 'screen positives' with the MMSE increased the AUC even further to 0.822 (95\% CI 0.691-0.953, p < 0.001).

\section{Discussion}

The growing burden of dementia, which carries great stigma, and grave social, legal and risk implications for sufferers [80], calls for clinical action to identify the disease in its earliest stages. Early detection of cognitive impairment in low-income countries that have competing health priorities requires the availability of valid measures requiring minimal investment in resources for their administration. In choosing the most suitable screening measures, the decision should be made whether the intention is to detect the presence of cognitive 
Ramlall et al.: The Sensitivity and Specificity of Subjective Memory Complaints and the SMRS, DECO, MMSE, SIS and CDT in Dementia Screening

impairment in a community setting (requiring a measure with high sensitivity), or to make a diagnosis in a high-risk, clinical sample which will require a measure that has high specificity [87]. Our study evaluated a range of screening measures with a view to identifying suitable measures with potential for utilization in local clinical settings.

Based on its clinical utility index, the single-domain subjective memory measures appear to be accurate assessments of subjective memory complaints [82] and have a 'good' value for ruling out a diagnosis but are rated as having a 'poor' value for ruling in a diagnosis of dementia [24]. Our study confirmed the utility of the SMCC as a good 'rule-out' measure in our population. The performance of both the SMC and SMCC in our study was superior to the $43 \%$ sensitivity and $85.8 \%$ specificity reported in a meta-analysis of SMC [74]. The differing performance between SMC and SMCC highlights the need for a standard definition of subjective memory impairment for research or clinical settings [55]. The advantage of the SMCC lies in its brevity of administration and simplicity in scoring. It may easily be used at a community level for screening by community health workers or primary health care nurses where there is a shortage of mental health professionals. In addition, SMCC has minimal training and resource costs, quick administration, easy interpretation and meets the criteria of a test for effective screening [9].

Once participants with subjective memory complaints have been identified, screening with a multidomain tool such as the MMSE would be advised. A meta-analysis of short screening tests in low-prevalence community settings also reported an overall sensitivity of $72 \%$ (95\% CI 60.4-82.3), and a specificity of 88.2\% (95\% CI 83.0-92.5) [79] for the MMSE. The performance of the MMSE in the current study sample was less robust. However, changing the recommended cutoff score of $\leq 23$ to $\leq 24$ would increase the sensitivity to $80 \%$ but decrease the specificity to $67.6 \%$. Despite its limitations, the MMSE may remain the best tool for primary care clinicians who want to rule in or rule out a diagnosis of dementia, provided the length of administration is acceptable [79]. The length of the MMSE and the training and skill required for its administration, scoring and interpretation may make it more suitable for use at a general hospital level as opposed to busy primary health care settings. While the simplicity and brevity [88] made the MMSE particularly suitable for use in low-resource settings, the recent copyrighting of this tool may make its use prohibitive for clinical and research applications in low-income countries.

The CDT, with an AUC of 0.732, also displayed good discriminant validity. The specificity displayed in our study (88.9\%) compares favorably with the published literature which reports a mean of $85 \%$. However, our sensitivity (44.4\%) was considerably lower than the published mean of $85 \%$ [89]. This difference may be due to this study employing the Rouleau scoring system. One study showed that the Watson method yielded sensitivity and specificity values of 59 and $70 \%$, respectively, while the Sutherland method yielded sensitivity and specificity values of 18 and $100 \%$, respectively, on the CDT in the same cohort of patients [90]. The high NPV of $95.0 \%$ in our study identifies the CDT as having a good 'rule-out' value.

The CDT, despite being classified as a single-domain test, can be used to compensate for some of the limitations of the MMSE. It can be applied in the screening of symptomatic individuals in whom the ceiling effect of the MMSE precludes conclusive screening. As the MMSE does not have an item that assesses executive functions, the CDT can be administered to make this assessment. The CDT has been shown to be moderately sensitive and a specific adjunct for detecting executive cognitive impairment in those with a normal MMSE [90]. The CDT is a simple test that has shown good internal consistency and interrater reliability as a measure of executive ability [86]. However, while it is easily administered, scoring systems, which can be both qualitative and quantitative, require some skill in application. In our study, the high specificity of the CDT (88.9\%) identifies it as being potentially useful for specialist clinical settings where there are mental health professionals. 
Ramlall et al.: The Sensitivity and Specificity of Subjective Memory Complaints and the SMRS, DECO, MMSE, SIS and CDT in Dementia Screening

As no measures have $100 \%$ sensitivity and $100 \%$ specificity [87], the ideal screening measure should attempt to achieve maximum sensitivity with maximum specificity, and adjusting the threshold scores should improve sensitivity at the expense of reduced specificity and vice versa $[87,91]$. By combining tests that evaluate complementary functions, their discriminant validity can be improved. The combination of the SMCC and MMSE using the logistic regression model provides the best discrimination (AUC >0.80). However, its application in clinical settings is impractical as the calculated scores are arbitrary values that do not share the attributes of the scales of the tests being combined [84]. Of the remaining 3 combination methods, conjunctive and compensatory combinations add minimal value to the predictive validity of the MMSE of SMCC alone, but sequential screening, as described earlier, improves the sensitivity of the MMSE and the specificity of the SMCC and may be the most practical and predictive approach in the local setting.

Neuropathological brain changes are present prior to the clinical manifestation of Alzheimer's dementia [18, 92]. MCI is an important stage in the Alzheimer's dementia continuum and although its course is variable, it is the first clinical harbinger of Alzheimer's dementia. Identifying screening measures that could identify individuals with MCI will create the opportunity to implement risk management strategies pending the availability of pharmacological agents for the prevention of progression to Alzheimer's dementia. The IQCODE has been shown to be useful in diagnosing Alzheimer's dementia, but was less effective in differentiating MCI from subjective memory complaint [93]. In our study, the MMSE, SMRS, SMCC and CDT display the potential to discriminate MCI from those with dementia and the controls (table 1). The sensitivity, specificity, PPV and NPV of these measures will be explored further for MCI screening.

\section{Recommendations and Limitations}

Multistage screening is 1 of 5 recognized models of dementia risk prediction [10, 38]. Establishing the presence of SMCC is a simple and effective first step in identifying symptomatic at-risk elderly. It can also be applied to medical patients in whom the presence of dementia should be excluded because cognitive impairment will impact on the care and outcome of comorbid medical conditions. Those screening positive can then be referred for a second level of more intensive screening at the general hospital level using the multidomain MMSE or CDT. Referral for specialist clinical assessments or expensive diagnostic investigations could then be determined by the results of the MMSE or CDT.

The study has some limitations in that the results may not be generalizable to community or clinical populations as our sample was drawn from a residential setting. Secondly, the sample was not demographically representative of the South African population as there was a majority of white patients and females. The inclusion criteria precluded participation by those who may have had severe dementia and were unable to engage in the various assessments.

\section{Conclusion}

A recent evaluation of the literature suggested that current risk models for dementia are poor at discriminating between 'at-risk' and 'not at-risk' individuals [10]. Recognition of dementia is ideally made during the early stage of the disease. This is also the time when the distinction between normal age-related cognitive decline and early dementia may be the most difficult to differentiate. Screening tools which have good discriminant validity are necessary to ensure that screening initiatives are both effective and efficient. External vali- 
Ramlall et al.: The Sensitivity and Specificity of Subjective Memory Complaints and the SMRS, DECO, MMSE, SIS and CDT in Dementia Screening

dation of our findings in larger residential samples and in community settings will be useful in confirming the reliability and validity of the assessed measures for widespread local application.

\section{Disclosure Statement}

There are no conflicts of interest.

\section{References}

1 Alzheimer's Disease International: The global economic impact of dementia. World Alzheimer Report. 2009. http://www.alz.co.uk/research/worldreport/.

2 Petersen RC, Stevens JC, Ganguli EG: Practice parameter: early detection of dementia: mild cognitive impairment (an evidence-based review): report of the Quality Standards Subcommittee of the American Academy of Neurology. Neurology 2001;56:1133-1142.

3 Ward A, Arrighi HM, Michels S, Cedarbaum JM: Mild cognitive impairment: disparity of incidence and prevalence estimates. Alzheimers Dement 2012;8:14-21.

4 Alzheimer's Disease International: The Benefits of Early Diagnosis and Intervention. World Alzheimer Report 2011. London, Alzheimer's Disease International, 2011.

5 Dias A, Patel V: Closing the treatment gap for dementia in India. Indian J Psychiatry 2009;51:S93-S97.

6 Ismail Z, Rajji TK, Shulman KI: Brief cognitive screening instruments: an update. Int J Geriatr Psychiatry 2010; 25:111-120.

7 Weimer DL, Sager MA: Early identification and treatment of Alzheimer's disease: social and fiscal outcomes. Alzheimers Dement 2009;5:215-226.

8 Wald NJ: Editorial: the definition of screening. J Med Screen 2001;8:1.

9 Herman CR, Gill HK, Eng J, Fajardo LL: Screening for preclinical disease: test and disease characteristics. AJR Am J Roentgenol 2002;179:825-831.

10 Stephan BC, Kurth T, Matthews FE, Brayne C, Dufouil C: Dementia risk prediction in the population: are screening models accurate? Nat Rev Neurol 2010;6:318-326.

11 Kalaria RN, Maestre GE, Arizaga R, Friedland RP, Galasko D, Hall K, et al: Alzheimer's disease and vascular dementia in developing countries: prevalence, management, and risk factors. Lancet Neurol 2008;7:812-826.

12 Sosa AL, Albanese E, Stephan BC, Dewey M, Acosta D, Ferri CP, et al: Prevalence, distribution, and impact of mild cognitive impairment in Latin America, China, and India: a 10/66 population-based study. PLoS Med 2012;9:e1001170.

13 Ritchie K, Fuhrer R: A comparative study of the performance of screening tests for senile dementia using receiver operating characteristics analysis. J Clin Epidemiol 1992;45:627-637.

14 Ardila A, Keating K: Cognitive abilities in different cultural contexts; in Uzzell BP, Ponton M, Ardila A (eds): International Handbook of Cross-Cultural Neuropsychology. Mahwah, Erlbaum, 2007.

15 Greenfield PM: You can't take it with you: why ability assessments don't cross cultures. Am Psychologist 1997; 52:1115-1124.

16 Kalula S, Petros G: Responses to dementia in less developed countries with a focus on South Africa. IFA Global Ageing 2011;7:31-39.

17 Reisberg B, Prichep L, Mosconi L, John ER, Glodzik-Sobanska L, Boksay I, et al: The pre-mild cognitive impairment, subjective cognitive impairment stage of Alzheimer's disease. Alzheimers Dement 2008;4(1 suppl 1):S98-S108.

18 Sperling RA, Aisen PS, Beckett LA, Bennett DA, Craft S, Fagan AM, et al: Toward defining the preclinical stages of Alzheimer's disease: recommendations from the National Institute on Aging-Alzheimer's Association workgroups on diagnostic guidelines for Alzheimer's disease. Alzheimers Dement 2011;7:280-292.

19 Jessen F, Wiese B, Bachmann C, Eifflaender-Gorfer S, Haller F, Kolsch H, et al: Prediction of dementia by subjective memory impairment: effects of severity and temporal association with cognitive impairment. Arch Gen Psychiatry 2010;67:414-422.

20 Bond J, Dickinson HO, Mathews F, Jagger C, Brayne C: Self-rated health status as a predictor of death, functional and cognitive impairment: a longitudinal cohort study. Eur J Ageing 2006;3:193-206.

21 Sargent-Cox K, Cherbuin N, Sachdev P, Anstey KJ: Subjective health and memory predictors of mild cognitive disorders and cognitive decline in ageing: the Personality and Total Health (PATH) through Life Study. Dement Geriatr Cogn Disord 2011;31:45-52.

22 Comijs HC, Deeg DJ, Dik MG, Twisk JW, Jonker C: Memory complaints; the association with psycho-affective and health problems and the role of personality characteristics. A 6-year follow-up study. J Affect Disord 2002; 72:157-165. 
Ramlall et al.: The Sensitivity and Specificity of Subjective Memory Complaints and the

SMRS, DECO, MMSE, SIS and CDT in Dementia Screening

23 Park MH, Min JY, Min HY, Lee HJ, Lee DH, Song MS: Subjective memory complaints and clinical characteristics in elderly Koreans: a questionnaire survey. Int J Nurs Stud 2007;44:1400-1405.

24 Mitchell AJ: The clinical significance of subjective memory complaints in the diagnosis of mild cognitive impairment and dementia: a meta-analysis. Int J Geriatr Psychiatry 2008;23:1191-1202.

25 Gallassi R, Bisulli A, Oppi F, Poda R, Di Felice C: Subjective cognitive complaints, neuropsychological performance, affective and behavioural symptoms in non-demented patients. Int J Geriatr Psychiatry 2008;23: 95-101.

26 Juncos-Rabadan O, Pereiro AX, Facal D, Rodriguez N, Lojo C, Caamano JA, et al: Prevalence and correlates of cognitive impairment in adults with subjective memory complaints in primary care centres. Dement Geriatr Cogn Disord 2012;33:226-232.

27 Ardila A: Cultural values underlying psychometric cognitive testing. Neuropsychol Rev 2005;15:185-195.

28 Griffin-Pierce T, Silverberg N, Connor D, Jim M, Peters J, Kaszniak A, et al: Challenges to the recognition and assessment of Alzheimer's disease in American Indians of the southwestern United States. Alzheimers Dement 2008;4:291-299.

29 Nell V: Constructs, Norms, and the Problem of Comparability. Cross-Cultural Neuropsychological Assessment. Mahwah, Erlbaum, 2000.

30 Minett TS, Da Silva RV, Ortiz KZ, Bertolucci PH: Subjective memory complaints in an elderly sample: a crosssectional study. Int J Geriatr Psychiatry 2008;23:49-54.

31 Treves TA, Verchovsky R, Klimovitzky S, Korczyn AD: Incidence of dementia in patients with subjective memory complaints. Int Psychogeriatr 2005;17:265-273.

32 Jonker C, Geerlings MI, Schmand B: Are memory complaints predictive for dementia? A review of clinical and population-based studies. Int J Geriatr Psychiatry 2000;15:983-991.

33 Reid LM, Maclullich AM: Subjective memory complaints and cognitive impairment in older people. Dement Geriatr Cogn Disord 2006;22:471-485.

34 de Groot JC, de Leeuw FE, Oudkerk M, Hofman A, Jolles J, Breteler MM: Cerebral white matter lesions and subjective cognitive dysfunction: the Rotterdam Scan Study. Neurology 2001;56:1539-1545.

35 Stewart R, Dufouil C, Godin O, Ritchie K, Maillard P, Delcroix N, et al: Neuroimaging correlates of subjective memory deficits in a community population. Neurology 2008;70:1601-1607.

36 Minett TS, Dean JL, Firbank M, English P, O’Brien JT: Subjective memory complaints, white-matter lesions, depressive symptoms, and cognition in elderly patients. Am J Geriatr Psychiatry 2005;13:665-671.

37 Folstein MF, Folstein SE, Mc Hugh PR: A practical method for grading the cognitive state of patients for the clinician. J Psychiatr Res 1975;12:189-198.

38 Li Wang MS, van Belle G, Crane PK, Kukull WA, Bowen JD, Mc Cormick WC, et al: Subjective memory deterioration and future dementia in people aged 65 and older. J Am Geriatr Soc 2004;52:2045-2051.

39 Ritchie K, Fuhrer R: The validation of an informant screening test for irreversible cognitive decline in the elderly: performance characteristics within a general population sample. Int J Geriatr Psychiatry 1996;11: 149-156.

40 Ramlall S, Chipps J, Bhigjee AI, Pillay BJ: Screening a heterogeneous elderly South African population for cognitive impairment: the utility and performance of the Mini-Mental State Examination, Six Item Screener, Subjective Memory Rating Scale and Deterioration Cognitive Observee. Afr J Psychiatry, in press.

41 Ramlall S, Chipps J, Pillay BJ, Bhigjee AI: Mild cognitive impairment and dementia in a heterogeneous elderly population: prevalence and risk profile. Afr J Psychiatry, in press.

42 Neri M, Rubichi S, DeVreese LP, Roth M, Cipolli C: Validation of the full and short forms of the CAMDEX interview for diagnosing dementia: evidence from a one-year follow-up study. Dement Geriatr Cogn Disord 1998;9:339-346.

43 Prince M, Ferri CP, Acosta D, Albanese E, Arizaga R, Dewey M, et al: The protocols for the 10/66 dementia research group population-based research programme. BMC Public Health 2007; 7:165.

44 Morris JC, Heyman A, Mohs RC, Hughes JP, van Belle G, Fillenbaum G, et al: The Consortium to Establish a Registry for Alzheimer's Disease (CERAD). 1. Clinical and neuropsychological assessment of Alzheimer's disease. Neurology 1989;39:1159-1165.

45 Neri M, Roth M, De Vreese LP, Rubichi S, Finelli C, Bolzani R, et al: The validity of informant reports in assessing the severity of dementia: evidence from the CAMDEX interview. Dement Geriatr Cogn Disord 1998;9:56-62.

46 Hall KS, Gao S, Emsley CL, Ogunniyi AO, Morgan O, Hendrie HC: Community screening interview for dementia (CSI 'D'); performance in five disparate study sites. Int J Geriatr Psychiatry 2000;15:521-531.

47 Jorm AF, Korten AE: Assessment of cognitive decline in the elderly by informant interview. Br J Psychiatry 1988;152:209-213.

48 Jorm AF: The Informant Questionnaire on cognitive decline in the elderly (IQCODE): a review. Int Psychogeriatr 2004;16:275-293.

49 American Psychiatric Association: Diagnostic and Statistical Manual of Mental Disorders - Text Revision, ed 4. Washington, American Psychiatric Association, 2000.

50 Winblad B, Palmer K, Kivipelto M, Jelic V, Fratiglioni L, Wahlund LO, et al: Mild cognitive impairment - Beyond controversies, towards a consensus: report of the International Working Group on Mild Cognitive Impairment. J Intern Med 2004;256:240-246. 
Ramlall et al.: The Sensitivity and Specificity of Subjective Memory Complaints and the

SMRS, DECO, MMSE, SIS and CDT in Dementia Screening

51 Ramlall S, Chipps J, Bhigjee AI, Pillay BJ: The discriminant validity of a neuropsychological battery of tests in diagnosing dementia and mild cognitive impairment in an elderly South African population. Unpublished. 2013.

52 Knopman DS, DeKosky ST, Cummings JL, Chui H, Corey-Bloom J, Relkin N, et al: Practice parameter: diagnosis of dementia (an evidence-based review): report of the Quality Standards Subcommittee of the American Academy of Neurology. Neurology 2001;56:1143-1153.

53 Alagiakrishnan K: Overcoming the barriers to the diagnosis of dementia. Postgrad Med 2010;122:105-111.

54 Ashford JW: Screening for memory disorders, dementia and Alzheimer's disease. Aging Health 2008;4:399432.

55 Abdulrab K, Heun R: Subjective memory impairment. A review of its definitions indicates the need for a comprehensive set of standardised and validated criteria. Eur Psychiatry 2008;23:321-330.

56 Hertzog C, Park DC, Morrell RW, Martin M: Ask and ye shall receive: behavioral specificity in the accuracy of subjective memory complaints. Appl Cogn Psychol 2000;14:257-275.

57 Amariglio RE, Townsend MK, Grodstein F, Sperling RA, Rentz DM: Specific subjective memory complaints in older persons may indicate poor cognitive function. J Am Geriatr Soc 2011;59:1612-1617.

58 Roth M, Tym E, Mountjoy CQ, Huppert FA, Hendrie H, Verma S, et al: CAMDEX. A standardised instrument for the diagnosis of mental disorder in the elderly with special reference to the early detection of dementia. Br J Psychiatry 1986;149:698-709.

59 de Jager CA, Budge MM: Stability and predictability of the classification of mild cognitive impairment as assessed by episodic memory test performance over time. Neurocase 2005;11:72-79.

60 Schmand B, Jonker C, Hooijer C, Lindeboom J: Subjective memory complaints may announce dementia. Neurology 1996;46:121-125.

61 Crook TH 3rd, Feher EP, Larrabee GJ: Assessment of memory complaint in age-associated memory impairment: the MAC-Q. Int Psychogeriatr 1992;4:165-176.

62 Mattos P, Lino V, Rizo L, Alfano A, Araujo C, Raggio R: Memory complaints and test performance in healthy elderly persons. Arq Neuropsiquiatr 2003;61:920-924.

63 Hanninen T, Reinikainen KJ, Helkala EL, Koivisto K, Mykkanen L, Laakso M, et al: Subjective memory complaints and personality traits in normal elderly subjects. J Am Geriatr Soc 1994;42:1-4.

64 Hanninen T, Hallikainen M, Koivisto K, Helkala EL, Reinikainen KJ, Soininen H, et al: A follow-up study of ageassociated memory impairment: neuropsychological predictors of dementia. J Am Geriatr Soc 1995;43:10071015.

65 Reid M, Parkinson L, Gibson R, Schofield P, D’Este C, Attia J, et al: Memory complaint questionnaire performed poorly as screening tool: validation against psychometric tests and affective measures. J Clin Epidemiol 2012; 65:199-205.

66 Vale FAC, Ballieiro-Jr AP, Silva-Filho JH: Memory Complaint Scale (MCS). Proposed tool for active systematic research. Dement Neuropsychol 2012;6:216-218.

67 Lenger V, de Villiers C, Louw SJ: Informant questionnaires as screening measures to detect dementia. A pilot study in the South African context. S Afr Med J 1996;86:737-741.

68 Jorm AF, Scott R, Cullen JS, MacKinnon AJ: Performance of the Informant Questionnaire on Cognitive Decline in the Elderly (IQCODE) as a screening test for dementia. Psychol Med 1991;21:785-790.

69 Mitchell AJ: A meta-analysis of the accuracy of the Mini-Mental State Examination in the detection of dementia and mild cognitive impairment. J Psychiatr Res 2009;43:411-431.

70 Scazufca M, Almeida OP, Vallada HP, Tasse WA, Menezes PR: Limitations of the Mini-Mental State Examination for screening dementia in a community with low socioeconomic status: results from the Sao Paulo Ageing and Health Study. Eur Arch Psychiatry Clin Neurosci 2009;259:8-15.

71 Escobar JI, Burnam A, Karno M, Forsythe A, Landsverk J, Golding JM: Use of the Mini-Mental State Examination (MMSE) in a community population of mixed ethnicity. Cultural and linguistic artifacts. J Nerv Ment Dis 1986; 174:607-614.

72 Callahan CM, Unverzagt FW, Hui SL, Perkins AJ, Hendrie HC: Six-item screener to identify cognitive impairment among potential subjects for clinical research. Med Care 2002;40:771-781.

73 Strauss E, Sherman MS, Spreen 0: A Compendium of Neuropsychological Tests, ed 3. New York, Oxford University Press, 2006.

74 Mitchell AJ, Malladi S: Screening and case-finding tools for the detection of dementia. 2. Evidence-based metaanalysis of single-domain tests. Am J Geriatr Psychiatry 2010;18:783-800.

75 Rouleau I, Salmon DP, Butters N, Kennedy C, McGuire K: Quantitative and qualitative analyses of clock drawings in Alzheimer's and Huntington's disease. Brain Cogn 1992;18:70-87.

76 Rouleau I, Salmon DP, Butters N: Longitudinal analysis of clock drawing in Alzheimer's disease patients. Brain Cogn 1996;31:17-34.

77 Agrell B, Dehlin 0: The clock drawing test. Age Ageing 1998;27:399-403.

78 Consensus report of the Working Group on: 'Molecular and Biochemical Markers of Alzheimer's Disease'. The Ronald and Nancy Reagan Research Institute of the Alzheimer's Association and the National Institute on Aging Working Group. Neurobiol Aging 1998;19:109-116. 
Ramlall et al.: The Sensitivity and Specificity of Subjective Memory Complaints and the SMRS, DECO, MMSE, SIS and CDT in Dementia Screening

79 Mitchell AJ, Malladi S: Screening and case finding tools for the detection of dementia. 1. Evidence-based metaanalysis of multidomain tests. Am J Geriatr Psychiatry 2010;18:759-782.

80 Flicker L, Logiudice D, Carlin JB, Ames D: The predictive value of dementia screening instruments in clinical populations. Int J Geriatr Psychiatry 1997;12:203-209.

81 Kukull WA, Larson EB, Teri L, Bowen J, McCormick W, Pfanschmidt ML: The Mini-Mental State Examination score and the clinical diagnosis of dementia. J Clin Epidemiol 1994;47:1061-1067.

82 Swets JA: Measuring the accuracy of diagnostic systems. Science 1988;240:1285-1293.

83 Schisterman EF, Perkins NJ, Liu A, Bondell H: Optimal cut-point and its corresponding Youden Index to discriminate individuals using pooled blood samples. Epidemiology 2005;16:73-81.

84 Mackinnon A MR: Combining cognitive testing and informant report to increase accuracy in screening for dementia. Am J Psychiatry 1998;155:1529-1535.

85 De Long ER, De Long DM, Clarke-Pearson DL: Comparing the areas under two or more correlated receiver operating characteristic curves: a nonparametric approach. Biometrics 1988;44:837-845.

86 Royall DR, Cordes JA, Polk M: CLOX: an executive clock drawing task. J Neurol Neurosurg Psychiatry 1998;64: 588-594.

87 Heun R, Papassotiropoulos A, Jennssen F: The validity of psychometric instruments for detection of dementia in the elderly general population. Int J Geriatr Psychiatry 1998;13:368-380.

88 Srinivasan S: The concise cognitive test for dementia screening: reliability and effects of demographic variables as compared to the mini mental state examination. Neurol India 2010;58:702-707.

89 Shulman KI: Clock-drawing: is it the ideal cognitive screening test? Int J Geriatr Psychiatry 2000;15:548-561.

90 Juby A, Tench S, Baker V: The value of clock drawing in identifying executive cognitive dysfunction in people with a normal Mini-Mental State Examination score. CMAJ 2002;167:859-864.

91 Brayne C, Calloway P: The case identification of dementia in the community: a comparison of methods. Int J Geriatr Psychiatry 1990;5:309-316.

92 Snowdon DA: Healthy aging and dementia: findings from the Nun Study. Ann Intern Med 2003;139:450-454.

93 Sikkes SA, van den Berg MT, Knol DL, de Lange-de Klerk ES, Scheltens P, Uitdehaag BM, et al: How useful is the IQCODE for discriminating between Alzheimer's disease, mild cognitive impairment and subjective memory complaints? Dement Geriatr Cogn Disord 2010;30:411-416. 